pueden persistir por semanas a meses. Estudios han revelado utilidad del manitol endovenoso.

\section{Envenenamiento paralítico}

Una toxicidad sistémica es rara pero puede ocasionar serias consecuencias. Es causada por la ingestión de una saxitoxina, usualmente por el consumo de mariscos contaminados, como: ostras, vieira, mejillones, almejas. Las saxitoxinas son producidas por varios dinoflagelados marinos, particularmente. Alexandrium tamarense.

Las manifestaciones clínicas incluyen: parálisis y hormigueo de la cara y cuello, cefalea, náuseas y debilidad muscular que puede llevar a falla respiratoria. Los síntomas habitualmente se presentan minutos después de la ingestión del alimento. El tratamiento es de soporte.

Botulismo: Enfermedad paralítica causada por una neurotoxina producida por la bacteria Clostridium botulinum. La neurotoxina es considerada la toxina más letal conocida, categorizada como A por el CDC, como uno de los agentes de bioterrorismo más peligrosos. Es causada por el consumo de alimentos que contienen la toxina botulínica (comida en lata mal envasada). Los síntomas incluyen pródromos: dolor abdominal, náuseas, vómitos, y posible diarrea, seguido de una latencia de 12 a 72 horas, para desarrollar síntomas neurológicos progresivos: diplopía, visión borrosa, ptosis, dificultad para tragar, debilidad muscular y eventualmente, falla respiratoria secundaria a la parálisis de los músculos respiratorios. La toxina ejerce sus efectos por bloqueo de la acetilcolina en las neuronas motoras. La falla respiratoria puede durar semanas a meses. El tratamiento es de soporte, incluyendo ventilación mecánica y antitoxina botulínica.

Comentario: Interesante artículo de revisión que establece las etiologías más frecuentes de infecciones asociadas al consumo de alimentos contaminados, los síntomas y su tratamiento más adecuado.

Es fundamental que todos los médicos clínicos estemos familiarizados con los diferentes síndromes asociados a este tipo de infecciones, para así estar alertas y permitirnos sospechar a tiempo el diagnóstico correcto, con el consiguiente óptimo tratamiento, dependiendo del posible agente causal.

Alejandra Massoc P. Hospital FACH, Santiago

\section{Infecciones por} Acinetobacter

Acinetobacter infection. MuñozPrice LS, Weinstein RA. N Engl J Med 2008; 358: 1271-81.
Introducción. Acinetobacter es un cocobacilo gram negativo que durante las tres pasadas décadas emergió como patógeno importante en todo el mundo. Un cuarto de las publicaciones en los últimos 20 años de Acinetobacter nosocomial han sido durante los años 2005 y 2006. Alarmantes son la habilidad de acumular diversos mecanismos de resistencia, la aparición de cepas resistentes a todos los antibacterianos comercialmente disponibles y la carencia de nuevos antimicrobianos en desarrollo. Acinetobacter fue descrito por primera vez en 1911. Su hábitat natural son la tierra y agua y ha sido aislado de alimentos, artrópodos y el ambiente. En humanos puede colonizar piel, heridas, tracto respiratorio y gastrointestinal. Algunas cepas pueden sobrevivir a la desecación ambiental durante semanas, característica que promueve la transmisión nosocomial a través de fomites. Acinetobacter es fácilmente identificado en el laboratorio. A. baumannii, A. calcoaceticus y A. lwoffii son las especies más frecuentes.

Mecanismos de resistencia. En cepas nosocomiales incluyen $\beta$-lactamasas, alteraciones de los canales (porinas) de la pared celular y bombas de eflujo. Acinetobacter baumannii puede llegar a ser resistente a quinolonas por mutación en genes $\operatorname{gyr} A$ y $\operatorname{part} C$ y a aminoglucósidos expresando enzimas modificadas. $\beta$ lactamasas $\mathrm{AmpC}$ son cefalosporinasas cromosomales intrínsecas de todos los A. baumannii. Generalmente tienen un nivel bajo de expresión pero, si se agrega una secuencia de inserción promotor (ISAba1) cerca del gen $\operatorname{ampC}$, aumenta la síntesis de $\beta$-lactamasas produciendo resistencia a cefalosporinas. Sobre los canales de porinas existe poca evidencia pero se sabe que la mutación de las proteínas de las porinas puede impedir el paso al espacio periplásmico. La sobre-expresión de bombas de eflujo puede disminuir la concentración de $\beta$-lactámicos en el espacio periplásmico. Para causar resistencia clínica las bombas de eflujo actúan junto con la sobre-expresión de $\beta$-lactamasas tipo AmpC o carbapenemasas. El problema clínico mayor es la adquisición de $\beta$-lactamasas, incluidas serino y metalo $\beta$-lactamasas que le confiere resistencia a carbapenems. Actualmente, el término "multiresistencia a fármacos" (en inglés multidrug resistance) en 
Acinetobacter no tiene una definición estandarizada. El término "panresistencia" ha sido usado para describir cepas resistentes a todos los antimicrobianos testeados (excepto colistín).

Epidemiología. Acinetobacter es un patógeno de climas calurosos y húmedos, ambiente característico de unidades de cuidados intensivos (UCI). Durante las dos pasadas décadas las infecciones por Acinetobacter sp han llegado a ser un problema nosocomial creciente en climas temperados. Cuidados de saludinfecciones asociadas. Las infecciones tienden a ocurrir en pacientes debilitados, la mayoría en UCI. Hospitalización prolongada y pacientes en ventilación mecánica son de alto riesgo. Otros factores para la colonización e infección son: cirugías recientes, cateterización vascular central, traqueostomía, alimentación enteral y tratamiento antimicrobiano con cefalosporinas de tercera generación, fluoroquinolonas y carbapenems. En brotes de Acinetobacter se han encontrado fuentes comunes de contaminación, particularmente contaminación respiratoria-terapia y equipos de ventilación, infecciones cruzadas por las manos del personal que ocasionalmente portan una cepa epidémica. Una vez introducido en el hospital, Acinetobacter sp generalmente tiene un patrón epidemiológico de brotes de cepas multiresistentes con la consecuente endemia de múltiples cepas y de cepa epidémica predominante en cualquier momento. Hospitalizaciones prolongadas podrían contribuir a la endemia de $A$. baumannii luego de un brote. La ocurrencia de brotes monoclonales en múltiples hospitales sugiere la diseminación interinstitucional, presumiblemente por el movimiento de pacientes del personal, exposición a fuentes comunes de contaminación de alimentos y equipos. Variación estacional. Desde 1974 el CDC ha reportado mayores índices de infecciones nosocomiales por Acinetobacter, en verano más que en otras estaciones. Posibles explicaciones incluye ambientes más calurosos y húmedos; en UCI podría ser prevenible la condensación de las unidades de aire acondicionado. Infecciones adquiridas en la comunidad. Han sido reportadas en ciertas áreas geográficas. Se desconoce la razón pero se podría deber a diferencias en temperatura y humedad lo que influye en la colonización por este agente. Personal militar. Se han reportado desde 1955 brotes de infecciones por Acinetobacter sp durante algunas guerras. La heteroclonicidad de las cepas y la reaparición de Acinetobacter sp en el personal participante en varias acciones militares los pasados 50 años sugiere múltiples causas incluyendo la comida local, contaminación de heridas en el campo de batalla, diseminación ambiental e infecciones cruzadas en el campo y hospitales de referencia. Desastres. Muchos desastres graves del último tiempo como el tsunami del sudeste asiático en el año 2004 sugieren incorporar a Acinetobacter sp como diagnóstico microbiológico diferencial en infecciones de tejidos blandos luego de la exposición a ambientes tropicales y que esas cepas importadas puedan causar diseminación de contaminación e infecciones cruzadas.

Manifestaciones clínicas. Neumonías asociadas a ventilación mecánica (NAVM) e infecciones del torrente sanguíneo son las manifestaciones clínicas más frecuente asociadas a Acinetobacter sp. Estos dos orígenes son las fuentes más frecuentes de bacteriemias cuyos crudos índices de mortalidad sólo pueden compararse a otros bacilos gramnegativos (28 a 32\%). En infecciones del torrente sanguíneo se ha visto que Acinetobacter sp se aisla frecuentemente con otros agentes que forman parte de microbiota comensal de la piel (Staphylococcus coagulasa negativa y Enterococcus sp). Esto podría corresponder a cepas contaminantes del ambiente. La NAVM debida a Acinetobacter sp ocurre mayoritariamente en UCI y es de inicio tardío. Los pacientes con estadías más en UCI hacen más infecciones por Acinetobacter sp que por otros bacilos gramnegativos. Estudios recientes muestran alta mortalidad en pacientes con infecciones por cepas multiresistentes pero cuando se toma en cuenta la gravedad de la enfermedad subyacente, la principal diferencia fue la estadía prolongada en UCI con infecciones por Acinetobacter sp multiresistente. Otro estudio no mostró diferencias entre infecciones por este y otros agentes, sugiriendo que las condiciones coexistentes fueron los mayores predictores de la mejoría y que en algunos casos habría sido un colonizante más que un patógeno.

Tratamiento. Las infecciones por Acinetobacter sp sensible han sido generalmente tratadas con cefalosporinas de amplio espectro asociadas a inhibidores de $\beta$-lactamasas (sulbactam) o carbapenémicos (existen reportes de susceptibilidades discordantes a carbapenémicos), asociados o no, a aminoglucósidos. La duración del tratamiento es generalmente similar a otras infecciones causadas por bacilos gramnegativos, mayoritariamente empírico y depende del sitio de la infección. Para infecciones causadas por agentes multirresistentes, la elección de antimicrobianos podría ser limitada. Las polimixinas B y E (colistín) son los agentes más activos in vitro. Son detergentes catiónicos que rompen las membranas citoplasmáticas. Fueron abandonadas durante los años 1960 y 1970 por problemas de nefro y neurotoxicidad. La emergencia de bacilos gramnegativos multiresistentes trajo a estos fármacos de vuelta durante los últimos años. Estudios recientes muestras menos toxicidad por el uso de menores dosis, distintas formulaciones y monitorización cuidadosa en UCI. Algunos estudios in vitro 
recientes han sugerido resistencia heterogénea en algunas cepas fenotípicamente sensibles de Acinetobacter sp. Tigeciclina, un nuevo antibacteriano (glicilciclina) ha demostrado ser activo in vitro y clinicamente frente a algunas cepas multiresistentes de A. baumannii. Sin embargo, ya se ha reportado el desarrollo de resistencia. Además, en algunos brotes de infección por Acinetobacter sp muchos aislados no fueron sensibles a tigeciclina. Sólo conclusiones limitadas se pueden obtener de los estudios de resistencia de Acinetobacter $\mathrm{sp}$, muchos de ellos retrospectivos, con series pequeñas de casos, infecciones variadas, etc. A pesar de lo anterior, en muchos de ellos colistín intravenoso mostró éxito, en $50 \%$ de los casos de neumonía. En infecciones del torrente sanguíneo los estudios son más limitados. Existe una serie grande durante un brote de 81 casos en Chicago, donde $49 \%$ no recibió tratamiento antimicrobiano o se inició, en $22 \%$ de los casos, cuando los cultivos se hicieron negativos. Esto sugiere que en algunos casos Acinetobacter sp podría ser sólo contaminación de la muestra. La administración de colistín intratecal ha sido exitosa en el tratamiento de infecciones del SNC. La penetración a meninges inflamadas es moderada mediante la administración venosa de colistín. Frente a infecciones por agentes multirresistentes, los médicos clínicos usan combinaciones de antimicrobianos. In vitro se ha demostrado efecto sinérgico o aditivo entre polimixinas e imipenem, rifampicina o azitromicina.

Control de infecciones. La primera meta para el control de infecciones por Acinetobacter sp multirresistente es reconocer tempranamente su presencia en hospitales o unidades de cuidados prolongados, con- trolando su diseminación agresivamente y previniendo el establecimiento de cepas endémicas. Las medidas de control se basan en experiencias de brotes y generalmente apuntan los principales modos de transmisión epidémica y el excesivo uso de antimicrobianos. El control es exitoso cuando una fuente común es identificada y eliminada. El aseo agresivo del ambiente ha sido la siguiente intervención más frecuente. Se ha clausurado una sección o unidad para realizar aseo, sistemáticamente los últimos 40 años, y el control de brotes ha sido mayor en infecciones por Acinetobacter que por otros agentes. Al aplicar múltiples medidas de aseo simultáneamente ha sido difícil asumir el efecto independiente de cada acción por separado. Sin embargo, la falla en mantener bajos niveles de de contaminación ambiental con de $A$. baumannii se relaciona con un aumento en el riesgo de colonización de los pacientes. Cuando no es posible identificar fuentes comunes ni reservorios, el control va a depender de las actividades de vigilancia y el aislamiento de contacto para los pacientes colonizados, mejoramiento en la higiene de manos del personal (generalmente la medida más difícil de implementar) y el cuidado aséptico de catéteres vasculares y tubos endotraqueales. Se ha reportado en algunos brotes como medida de control reducir la prescripción de antibacterianos de amplio espectro como fluoroquinolonas o carbapenémicos. Sin embargo, la aplicación de múltiples intervenciones complica la interpretación de estos datos. Finalmente, la decolonización de los pacientes mediante la limpieza con clorhexidina o el uso de polimixinas tópicas, orales o inhalatorias han sido medidas coayudantes de control que garantizan evaluación.

Maggie Vecchiola $\boldsymbol{H}$. Hospital San José, Universidad Mayor Santiago 